HELMINTHOLOGIA, 53, 4: 326 - 330, 2016

\title{
Helminths in rodents from Wet Markets in Thailand
}

\section{A. RIBAS ${ }^{1 *}$, W. SAIJUNTHA ${ }^{2}$, T. AGATSUMA ${ }^{3}$, C. THONGJUN ${ }^{1}$, K. LAMSAN $^{1}$, S. POONLAPHDECHA ${ }^{1}$}

'Biodiversity Research Group, Faculty of Science, Udon Thani Rajabhat University, Udon Thani 41000, Thailand, *E-mail: alexisribas@hotmail.com; ${ }^{2}$ Walai Rukhavej Botanical Research Institute (WRBRI), Mahasarakham University, Maha Sarakham 44150, Thailand; 'ivision of Environmental Health Sciences, Kochi Medical School, Kochi University, Oko, Nankoku 783-8505, Japan;

\section{Article info}

Received July 1, 2016 Accepted October 26, 2016

\begin{abstract}
Summary
Only a few surveys have ever been carried out of the helminths of the commensal rodents found in the traditional wet markets that play such an important part of daily life in South-east Asia. The potential of rodents as reservoirs of zoonoses including helminths is of great interest since in these markets humans and rodents come into closer contact than in other environments and food may be indirectly contaminated via rodent faeces. Helminths in a total of 98 rats belonging to two species (Rattus norvegicus and Rattus exulans) were surveyed in eight traditional wet markets in Udon Thani, Thailand. Thirteen species of helminths were recovered, seven of which are potentially zoonotic, with an overall prevalence of $89.8 \%$. Our results show that rodents in wet markets could pose a threat to human health as potential reservoirs of zoonotic helminthiases.
\end{abstract}

Keywords: Norwegian rat; Pacific rat; zoonoses; wet markets

\section{Introduction}

In South-east Asia (SEA) the traditional wet markets that sell fresh and cooked products for human consumption are an important part of daily life. Stalls are enclosed in permanent roofed structures that provide a stable habitat - i.e. food is available all year - for the successful survival and reproduction of commensal rodents. The study of possible rodent-borne zoonoses is of interest as it has been reported previously that in the same study sites (Ribas, et al., 2016) rodents are carriers and potential transmitters of Salmonella to humans. The role of rodents as reservoirs of helminth zoonoses in SEA has been reviewed by Chaisiri et al. (2015). The prevalence of helminths in humans in Thailand should not be underestimated as a prevalence of $18.1 \%$ was found by the last National Survey (Wongsaroj, 2015); some of these helminths are associated with rodents, the host species that are the object of the present study.

Surveys of helminths in wild rodents in SEA including Thailand have become increasingly common in recent years. Yet, although surveys of the rodents in antrophized habitats such as villages and associated habitats (rice fields and plantations) have been conducted, data from urban environments is still very limited. To date, studies of rodents in wet markets in SEA are limited to just two studies. Firstly, five wet markets were studied in Kuala Lumpur in insular Malaysia by Paramasvaran et al. (2009), who detected 97 rodents belonging to three species: $R$. $r$. diardii, a taxon that, according Pagès et al. (2010), should be considered as a Rattus sp. pending a definitive name, $R$. norvegicus Berkenhout, 1769 and $R$. exulans (Peale, 1848). A second study in insular SEA in the Philippines by Claveria et al. (2005) is of limited interest as its sampling effort (twelve rats) was low and rats were not identified to species level (hosts were simply described as Rattus spp.); in addition these authors provided no details of the number of studied wet markets. Finally, a third study in Taiwan, outside SEA but still in Asia (Tung et al., 2013), analyzed 51 rats (R. norvegicus and $R$. rattus) in traditional wet markets. Aside from these three surveys, 
no other information was found despite an extensive literature review (Veciana, 2016). Also of interest is the study by Mohd Zain et al. (2012) of $R$. norvegicus and $R$. rattus Linnaeus, 1758 (probably Rattus sp. according Pagès et al. (2010)) in Kuala Lampur; however in this latter study collection sites were not characterized. Thus, in light of this lack of previous information, the aim of the present study was to fill the gaps in the knowledge of the role of rodents as reservoirs of zoonotic helminthiases in traditional wet markets in SEA.

\section{Materials and Methods}

In mid-July to mid-August 2014 traps for rodents were set in eight traditional wet markets in Udon Thani (Udon Thani province, Thailand) (see methodological details in Ribas et al., 2016). Trapped animals were euthanized and dissected following international standards (American Veterinary Medical Association Council on Research). These protocols, which maximize animal care and prioritize the health and safety of field parasitologists, generate good-quality data (Herbreteau, et al., 2011). The study was approved by the Udon Thani Rajabhat University Animal Care and Ethical Use Committee. The viscera (GI tract, liver and lungs) were separated and dissected under a binocular microscope to identify and count helminths. Cestodes were stained with Semichon acetocarmine, dehydrated in alcohol, cleared in xylene and mounted in Canada balsam. Nematodes and acanthocephalans were mounted temporarily in Amann lactophenol. All helminths were identified by their morphology and morphometry according to the literature. Parasitation by Capillaria hepatica (Bancroft, 1893) was diagnosed macroscopically by the observation of whitish livers and then confirmed microscopically (categorized as positive or negative) by the observation of the typically bi-polar eggs in lactophenol. Liver cysts were dissected to confirm the presence of $H$. taeniaeformis larvae, identified by their characteristic rostellar hooks (Lavikainen et al., 2016). Some of the recovered helminths species have not yet been identified to species level since more material is still needed for full identification and comparison, and because our aim was essentially to study zoonotic helminths. The ecological terminology and quantitative parameters used followed Bush et al. (1997). Descriptive parameters and confidence intervals were calculated using Quantitative parasitology (Reiczigel \& Rózsa, 2005). In addition to the morphological and metrical traits (Aplin et al., 2003; Marshall, 1988), for host identification a piece of muscle tissue from each rodent was preserved in absolute ethanol to use the CO1 region for molecular identification (details of protocol in (Ribas et al., 2016).

\section{Results}

A total of 98 rodents were collected from the eight sampled markets. The molecular study of the hosts confirmed the presence of two rat species, 88 Norwegian rats ( $R$. norvegicus) and 10 Pacific rats ( $R$. exulans). The number of rodents collected in each market varied from seven to 21 . The overall prevalence of gastrointestinal helminth infection was $89.8 \%$ (95\% Cl: 82.0 - 95.0). The thirteen helminth species recovered included four cestodes, seven nematodes and one acanthocephalan (see details in Table 1).

\section{Discussion}

The two studied rodents are synanthropic and act as reservoirs in the spread of several diseases (Morand et al., 2015; Wells et al., 2015). Thus, both species are likely to be found in cities in SEA. The aforementioned studies of SEA markets (Claveria et al., 2005) (Paramasvaran et al., 2009; Tung et al., 2013), as well as in urban habitats (Mohd Zain et al., 2012), report the presence of the same zoonotic helminths as recovered in the present study (see details in Table 1).

According to the review by Chaisiri et al. (2015), four of our recovered helminths $(H$. diminuta, $H$. nana, Raillietina sp. and $M$. monoliformis) are potentially zoonotic species. A fifth gastrointestinal helminth (G. neoplasticum), not studied by Chaisiri et al. (2015), is also a potentially zoonotic species and has been reported in humans in Thailand by Pasuralertsakul et al. (2008). Nevertheless, reported cases of infestation in humans by this species worldwide are limited to just 40 - 50 reports (Wilson et al., 2001). We found a sixth zoonotic species, the lung nematode A. cantonensis, that was not included in the review by Chaisiri et al. (2015) given that these authors only studied gastrointestinal helminths. This nematode causes human eosinophilic meningitis, and human cases have been reported in Thailand, mostly in the northeastern provinces (Eamsobhana, 2013) such as our study area. Pipitgool et al. (1997) report the presence of $A$. cantonensis in snails in Udon Thani province and in rodents; nevertheless, the methodology used in these surveys is not described in detail (i.e. it is not possible to identify the surveyed habitats or the host to species level). The market where this lungworm was found backs onto railway tracks and an unpaved area with soil and vegetation that could allow snails to survive and act as intermediate hosts. A seventh potentially zoonotic species is the liver nematode $C$. hepatica that in humans can cause the rare hepatic capillariosis, a sanitary problem caused by consuming food contaminated with parasite eggs. In our study sites humans are usually infected after ingesting embryonated eggs in fecal-contaminated food (Tesana et al., 2007). High prevalences of $C$. hepatica in wet markets in comparison with rodents in the wild are evident in SEA. Brown et al. (1975) surveyed 6,498 rodents in Indonesia and only 31 (0.5\%) were positive for C. hepatica. A study by Liat et al. (1977) in Malaysia analyzed 1,258 rodents and detected higher prevalences in $R$. norvegicus (8/26) captured in houses and lower prevalences in forest rodents $(1.54-8 \%)$. Nevertheless, the habitats in which captures were performed are not well defined and so it is not easy to compare these author's results with those of the present study. In the Brazilian Amazon, Camargo et al. (2010) used indirect 


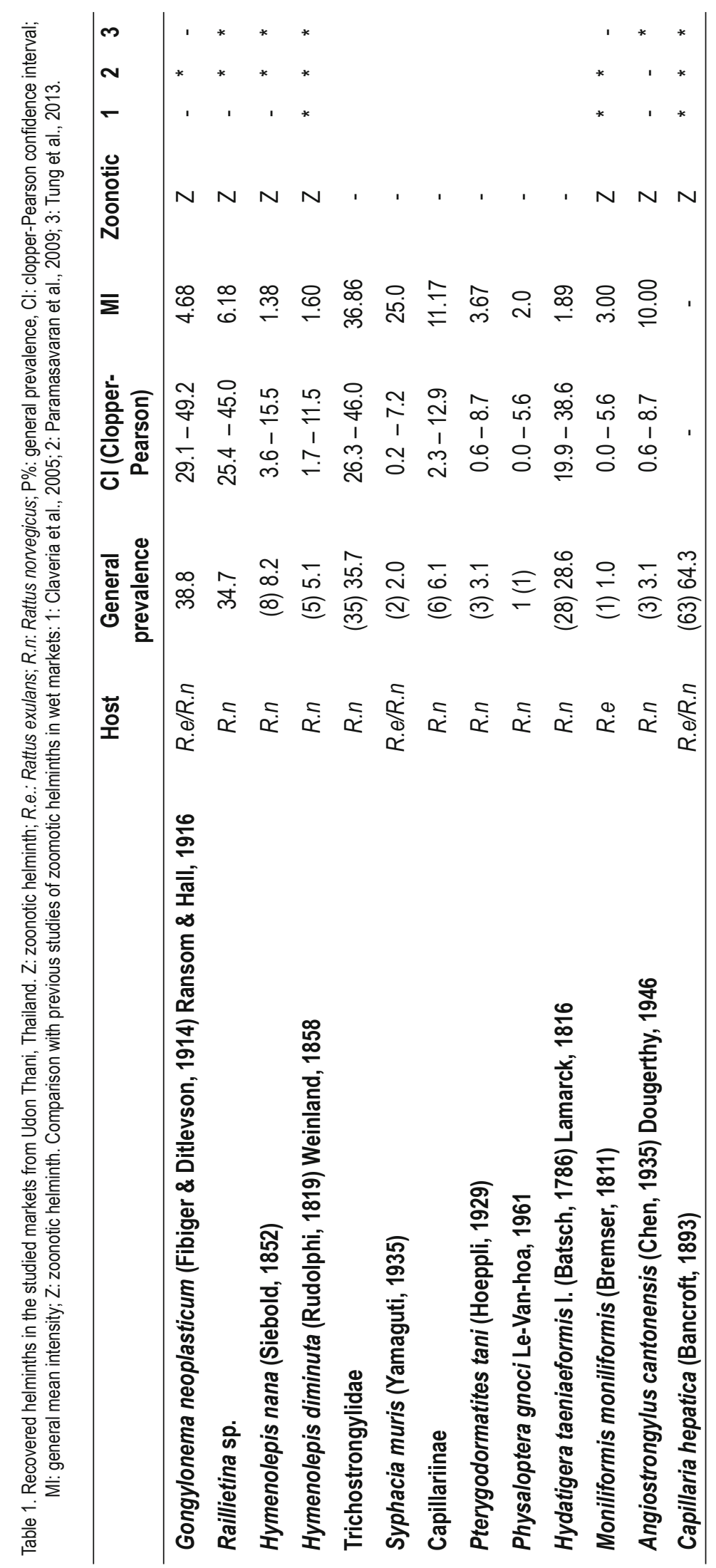


immunofluorescence techniques to establish an association between infected rodents and the incidence of hepatic capillariosis in workers in markets where there is a high incidence of $C$. hepatica in rodents. Although the high prevalence of $C$. hepatica in commensal rodents may increase the health risk in humans, to date human seroprevalence has not been examined in SEA.

Our study detected all the rodent-borne zoonotic nematodes and cestodes reported by Chaisiri et al. (2015) except Cyclodontostomum purvisi. Thus, there can be no doubt that in the studied wet markets there is a potentially high risk of rodent-borne transmission. The cockroaches that have been observed in the studied markets act as mechanical dispersers of helminth eggs (Young and Babero 1975; Chamavit et al., 2011). In addition, cockroaches also probably play an essential role in maintaining the life cycles of several species of helminths in wet markets as the majority of isolated helminth species require an arthropod as an intermediate host. Thus, the elimination of cockroaches could be an indirect way of reducing the number of rodent-borne helminths in wet markets. In conclusion, our results highlight the need to intervene to reduce rodent populations in wet markets in Thailand and in other countries where these markets are commonplace given that the rats that inhabit them are potential reservoirs of zoonotic diseases.

\section{Acknowledgements}

This study was supported by a grant from the Research and Development Institute, Udon Thani Rajabhat University and would not have been possible without the enthusiastic work of UDRU students.

\section{References}

Aplin, K.P., Brown, P.R., Jacob, J., Krebs, C.J., Singleton, G.R. (2003): Field Methods for Rodent Studies in Asia and the Indo-Pacific. Canberra, Australia, ACIAR Monograph, 100 pp.

Brown, R.J., Carney, W.P., Van, Peenen, P.F., Cross, J.H., Saroso, J.S. (1975): Capillariasis in wild rats of Indonesia. Southeast Asian J. Trop. Med. Public Health, 6(2): 219 - 222

Bush, A.O., Lafferty, K.D., LotZ, J.M., Shostak, A.W. (1997): Parasitology meets ecology on its own terms: Margolis et al. revisited. J. Parasitol., 83(4): 575 - 583

Camargo, L.M., Camargo, J., Vera, L.J., Barreto, P., Tourinho, E.K., De SouzA, M.M. (2010): Capillariaisis (Trichurida, Trichinellidae, Capillaria hepatica) in the Brazilian Amazon: low pathogenicity, low infectivity and a novel mode of transmission. Parasit. Vectors, 3(11). DOI:10.1186/1756-3305-3-11

Chaisiri, K., SiRibat, P., Ribas, A., Morand, S. (2015): Potentially zoonotic helminthiases of murid rodents from the Indo-Chinese Peninsula: impact of habitat and the risk of human infection. Vector Borne and Zoonotic Dis., 15(1): 73 - 85. DOI:10.1089/ vbz.2014.1619

Chamavit, P., Sahaisook P., Niamnuy, N. (2011): The majority of cock- roaches from the Samutprakarn Province of Thailand are carriers of parasitic organisms." EXCLI Journal, 10: 218 - 222

Claveria, F.G., Causapin, J., De Guzman, M.A., Toledo, M.G., SaLIBAY, C. (2005): Parasite biodiversity in Rattus spp. caught in wet markets. Southeast Asian J. Trop. Med. Public Health, 36(suppl 4): $146-148$

Eamsobhana, P. (2013): Angiostrongyliasis in Thailand: epidemiology and laboratory investigations. Hawaii J. Med. Public Health, 72(6 Suppl 2): 28 - 32

Herbreteau, V., Jittapalapong, S., Rerkamnuaychoke, W., Chaval, Y., Cosson, J.F. Morand, S. (2011): Protocols for Field and Laboratory Rodent Studies. Bangkok, Thailand, Kasetsart University Press, $56 \mathrm{pp}$.

LaVIKaInen, A., Iwaki, T., Haukisalmi, V., KonyaeV, S.V., Casiraghi, M., Dokuchaev, N.E., Galimberti, A., Halajian, A., Henttonen, H., Ichikawa-Sekı, M., Itagaki, T., Krivopalov, A.V., Meri, S., Morand, S., Näreaho, A., Olsson, G.E., Ribas, A., Terefe, Y., NakaO, M. (2016): Reappraisal of Hydatigera taeniaeformis (Batsch, 1786) (Cestoda: Taeniidae) sensu lato with description of Hydatigera kamiyai $\mathrm{n}$. sp. Int. J. Parasitol, DOI:10.1016/j.jpara.2016.01.009

Liat, L.B., Fong, Y.L., KRISHnASAmy, M. (1977): Capillaria hepatica infection of wild rodents in Peninsular Malaysia. Southeast Asian J. Trop. Med. Public Health, 8(3): 354 - 58

Marshall, J.T. (1988): Family Muridae: Rats and Mice. In: LeKAGUL, B., Mc Neely, J.A. (Eds) Mammals of Thailand, Bangkok, Thailand: Association for the Conservation of Wildlife, Sahakarnbhat Co, pp. $397-487$

Mohd Zain, S.N., Behnke, J.M., LewIS, J.W. (2012): Helminth communities from two urban rat populations in Kuala Lumpur, Malaysia. Parasit. Vectors, 5(1): 47. DOI:10.1186/1756-3305-5-47

Morand, S., Bordes, F., Chen, H.W., Claude, J., Cosson, J.F., Galan, M., Czirják, G.Á., Greenwood, A.D., Latinne, A., Michaux, J., RiBAs, A. (2015): Global parasite and Rattus rodent invasions: the consequences for rodent-borne diseases no title. Integr. Zool., 10(5): 409 - 423. DOI: 10.1111/1749-4877.12143

Pagès, M., Chaval, Y., Herbreteau, V., Waengsothorn, S., Cosson, J.F., Hugot, J.P., Morand, S., Michaux, J. (2010): Revisiting the taxonomy of the Rattini tribe: a phylogeny-based delimitation of species boundaries. BMC Evol. Biol., 10: 184. DOI:10.1186/14712148-10-184

Paramasvaran, S., Sani, R.A., Hassan, L., Hanjeet, K., Krishnasamy, M., John, J., Santhana, R., Sumarni, M.G., Lim, K.H. (2009): Endo-parasite fauna of rodents caught in five wet markets in Kuala Lumpur and its potential zoonotic implications. Trop. Biomed., 26(1): $67-72$

Pasuralertsakul, S., Yaicharoen, R., Sripochange, S. (2008): Spurious human infection with Gongylonema: nine cases reported from Thailand. Ann. Trop. Med. Parasitol., 102(5): 455 -457. DOI:10.1179/136485908X300869

Pipitgool, V., Sithithaworn, P., Pongmuttasaya, P., Hinz, E. (1997): Angiostrongylus infections in rats and snails in northeast Thailand. SoutheastAsian J. Trop. Med. Public Health, 28(Suppl 1): 190-193 
Reıczıgel, J., Rózsa, L. (2005): Quantitative Parasitology 3.0. Budapest, Hungary

Ribas, A., Saijuntha, W., Agatsuma, T., Prantlová, V., PoonlaphdeCHA, S. (2016): Rodents as a source of Salmonella contamination in wet markets in Thailand." Vector Borne Zoonotic Dis. 16 (8): 537 - 540. doi:10.1089/vbz.2015.1894

Tesana, S., Puapairoj, A., Saeseow, O. (2007): Granulomatous, hepatolithiasis and hepatomegaly caused by Capillaria hepatica infection: first case report of Thailand. Southeast Asian J. Trop. Med. Public Health, 38(4): 636 - 640

Tung, K.C., HsiaO, F.C., Wang, K.S., Yang, C.H., Lal, C.H. (2013): Study of the endoparasitic fauna of commensal rats and shrews caught in traditional wet markets in Taichung City, Taiwan. J. Microbiol. Immunol. Infect., 46(2): 85 - 88. DOl:10.1016/j. jmii.2012.01.012

VeCIANA, M. (2016): Noves dades parasitològiques en micromamífers (insectivors i rosegadors) del Sud-Est Asiàtic (Cambo- dja, Laos i Tailàndia). [New parasitological data on small mammals (insectivores and rodents) from South-east Asia (Cambodia, Laos and Thailand]. PhD thesis, Spain, Barcelona: Universitat de Barcelona (In Catalan)

Wells, K., O'hara, R.B., Morand, S., Lessard, J.P., Ribas, A. (2015): The importance of parasite geography and spillover effects for global patterns of host-parasite associations in two invasive species. Divers. Distrib., 21(4): 477 - 486. DOI:10.1111/ddi.12297 Wilson, M. E., Lorente, C. A., Allen, J. E., Eberhard, M. L. (2001): Gongylonema infection of the mouth in a resident of Cambridge, Massachusetts. Clin. Infect. Dis., 32(9): 1378 - 1380. DOI:10.1086/319991

Wongsaroj, T., NithikathKul, C., RojkitIKUl, W., Nakal, W., Royal, L., Rammasut, P. (2014): National survey of helminthiasis in Thailand. Asian Biomed., 8(6): 779 - 783. DOI:10.5372/1905-7415.806.357 Young, P.L., Babero, B.B. (1975): Studies on the transmission of helminth ova by cockroaches. Proc Okla Acad Sci 55: 169 - 174 